Bennett, D.A. 5

Bharucha, N. 7

Bueno-de-Mesquita, B. 25

Copetti, M. 59

Fiest, K.M. 16

Fontana, A. 59

Gallo, V. 25

Graziano, G. 59

Jansen, E. 25

Jetté, N. 16
Liu, M. 50

Logroscino, G. 5

Lucisano, G. 59

Nyssen, O.P. 25

Odermatt, P. 7

Otahal, P. 39

Patten, S.B. 16

Pellegrini, F. 59

Preux, P.-M. 7

Pringsheim, T. 16

Scardapane, M. 59

Siena, F. 59

Simpson, S., Jr. 39

Svenson, L.W. 16

Syed, A. 25
Takeda, A. 25

Taylor, B. 39

van der Mei, I.A.F. 39

Veneziani, F. 59

Wang, D. 50

Winzenberg, T. 39

Zhang, J. 50

\title{
Subject Index Vol. 42, No. 1, 2014
}

Acupuncture 50

Advanced techniques 59

Bayesian approaches 59

Burden of epilepsy 7

Carotenoids 25

Complementary therapy 50

Data pooling 59

Developing countries 7
Environment 39

Epidemiology 16

Exact methods 59

Gene 39

Generalized linear mixed models 59

Lutein 25

Meta-analysis/es 7, 16, 25, 39, 50, 59

Meta-regression 16

Neurological disease 39
Overview 50

Parkinson's disease 25

Stroke 50

Systematic review(s) 7, 16, 50

Treatment gap 7

Vitamin A 25

(C) 2013 S. Karger AG, Basel 